\title{
Dasymetric Mapping as a Tool to Assess the Spatial Distribution of Population in Jeddah City (Kingdom of Saudi Arabia)
}

\author{
M. H. Hamza*, A. S. Al-Thubaiti, M. Dhieb, A. Bel Haj Ali, M. S. Garbouj, M. Ajmi \\ Department of Geography and Geographic Information Systems, Faculty of Arts, King Abdulaziz University, Jeddah, KSA \\ Email: *mhhamza@kau.edu.sa
}

How to cite this paper: Hamza, M. H., AlThubaiti, A. S., Dhieb, M., Ali, A. B. H., Garbouj, M. S., \& Ajmi, M. (2016). Dasymetric Mapping as a Tool to Assess the Spatial Distribution of Population in Jeddah City (Kingdom of Saudi Arabia). Current Urban Studies, 4, 329-342.

http://dx.doi.org/10.4236/cus.2016.43022

Received: June 3, 2016

Accepted: September 25, 2016

Published: September 28, 2016

Copyright $\odot 2016$ by authors and Scientific Research Publishing Inc. This work is licensed under the Creative Commons Attribution International License (CC BY 4.0).

http://creativecommons.org/licenses/by/4.0/

(c) (i) Open Access

\section{Abstract}

It is well-known that, when dealing with density of population, most of the proposed maps choose the easiest and probably the most understandable cartographic method, i.e. the choropleth method. Nevertheless, for heterogonous spaces and those observing intense spatial dynamic, it is proven that this method has many lacks and deficiencies. This is the case of Jeddah city (the second largest city in Saudi Arabia), which is a very contrasted urban place with regards to its social structure, spatial organization and land use besides the fact that it witnesses a profound and continuous urban growth. Yet, most of the planning decisions are often taken on these types of maps and may mislead the urban planners. In this context, the dasymetric maps reveal very useful because they may give the real distribution of the population. Therefore, we think that establishing a dasymetric map at a convenient scale with regards to the results of satellite image processing may help the planners and the geographers as well as the common users. Indeed, this method may be an interesting alternative to the classic choropleth map. First it may improve our estimations towards the density within the various areas of the districts. Second it may refine the original enumeration units often using the administrative apportionment and therefore help the planning and agricultural agencies when establishing their base maps. The satellite image processing and GIS were used as tools in this study.

\section{Keywords}

Jeddah City, Kingdom of Saudi Arabia, Choropleth Map, Dasymetric Map, Satellite Image Processing, GIS

\section{Introduction}

Sustainable development requires access to data, information and knowledge about the 
study area. Often referred to as geographical or spatial data, is the information tied to a specific location, this one is an indispensable part of the available knowledge at modern science of Information and Communication Technology (Ajmi et al., 2014). Remote sensing and GIS will be used in the present study and help as ancillary data to establish an accurate population density map of Jeddah City, located on the coast of the Red Sea and which is the second largest city in Saudi Arabia after the capital city, Riyadh. Jeddah City is divided into is into 95 districts (Figure 1), its population is currently estimated around 3.4 million and constitutes one of the most important commercial urban poles in Saudi Arabia.

The assessment of population density will be done through the establishment and the comparison of both choropleth and dasymetric maps of Jeddah City based on the land use distribution with regards to the results of satellite image processing. The dasymetric mapping is a thematic mapping method developed and named in 1911 by Veniamin Petrovich Semenov-Tyan-Shansky and popularised by J.K. Wright (Petrov, 2012). Since that date, several attempts to implement the method through various spaces whether national, regional or urban with a certain degree of success. The term "dasymetric mapping" was first used by Russian geographers who described dasymetric maps as

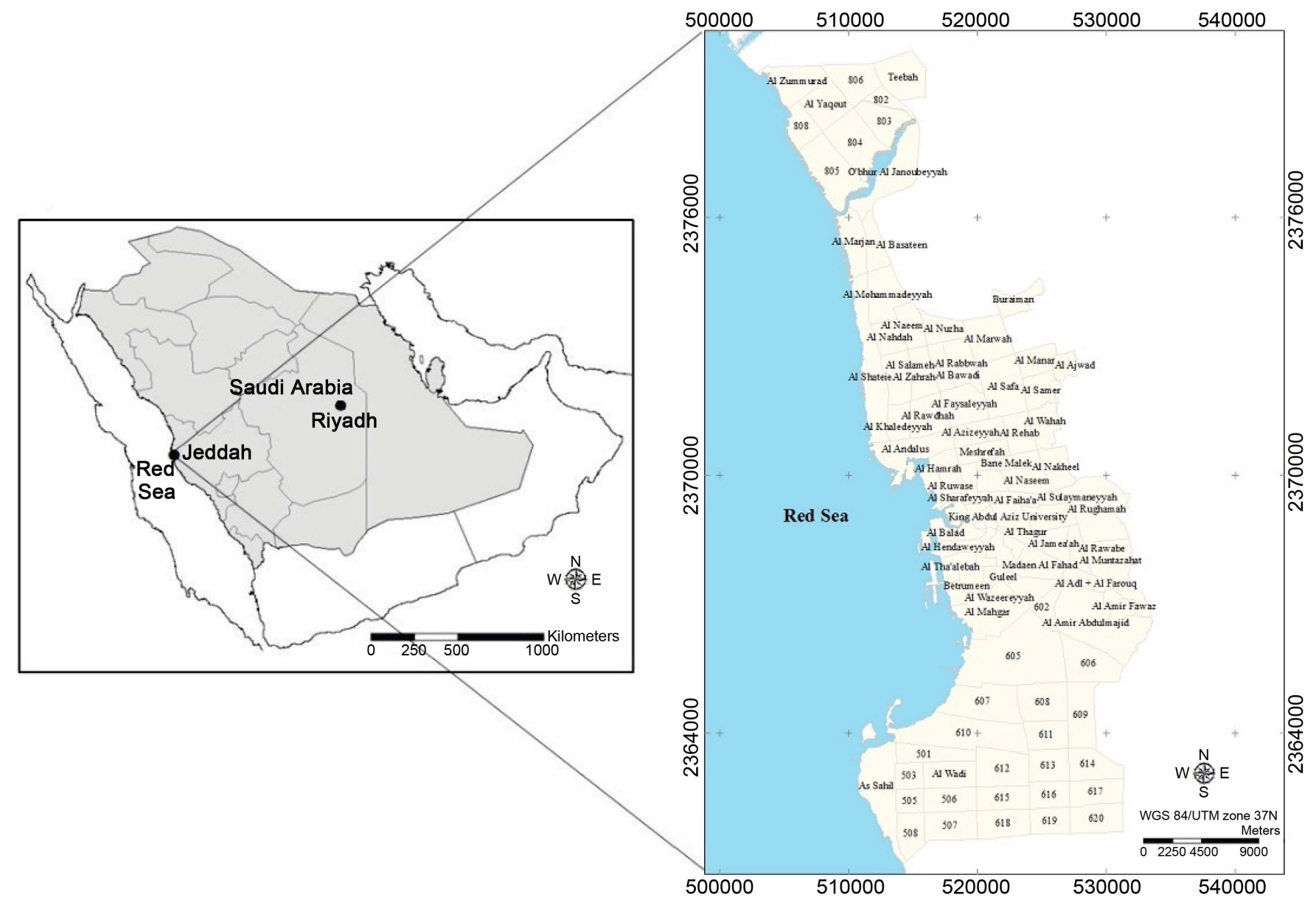

Figure 1. Study area. 
density measuring maps (Wright, 1936). Dasymetric mapping is used in Cartography for population density over other methods, because of its ability to realistically place data over geography (Dhieb, 1991a, 1991b, 1995). This method can improve accuracy of traditional choropleth maps usually used in this field. The dasymetric method was applied by many researchers around the world (McCleary Jr., 1969; Sleeter and Gould, 2007; Jaullt and Serradj, 2011).

The information generated from a dasymetric population density map could provide useful assistance to district administrations, especially those responsible for regional or city development and land management (Bielecka, 2005). The Spot 5 satellite image of Jeddah City used in the present study will be classified using the Spectral Angle Mapper supervised classification method. The obtained land use image will be updated using Google Earth Pro and then transferred to ArcGIS ESRI GIS software into vector format.

\section{Data Description}

Different data types were used in this study. First, the statistical population data in the different districts of Jeddah City were taken from the services of Saudi Arabian central department of statistics and information based on districts population numbers (2014). The population number was first drafty represented by district on a simple graded-circles map based on the Flannery method of designing in order to fit the perceptual rules (Figure 2). Of course, the map doesn't take into account the difference of areas of the districts which spread from 0.4309 to $34.817 \mathrm{sq} \cdot \mathrm{km}$, that to say, a ratio from 1 to 80.8 , whereas difference from the less populated district to the most populated fan out from 118 to 159,484 , a ratio scattering from 1 to 1351.5 . The map shows noteworthy distances between central and surrounding districts.

Second, the base map of Jeddah City uses the districts contours as well as the inner subdivisions limits. These limits may furtherly reveal very useful when calculating densities over effective uninhabited areas and therefore implementing the dasymetric map method.

Third, as ancillary basic data, the use of the satellite image and Google Earth images allowed the extraction of the updated inhabited zones from the study area to calculate the real densities of population. The purpose is to distribute the population only on the populated zones. The satellite image of Jeddah City (SPOT 5) was taken on July $30^{\text {th }}, 2010$, with a 2.5 meters resolution; it was used for representing the land use and then the real population density. Google Earth Pro was used to update field land use data.

Therefore, instead of using administrative units portraying the densities through various choropleth maps, the dasymetric maps are based on effective homogeneous likelihood zones (Dhieb, 1991a, 1991b). These new subdivisions may be portrayed with or without referring to the original limits. In our case, in order to make the original subdivisions stable in the users' minds and perception, we preferred keeping all together the Districts limits with the new limits. 


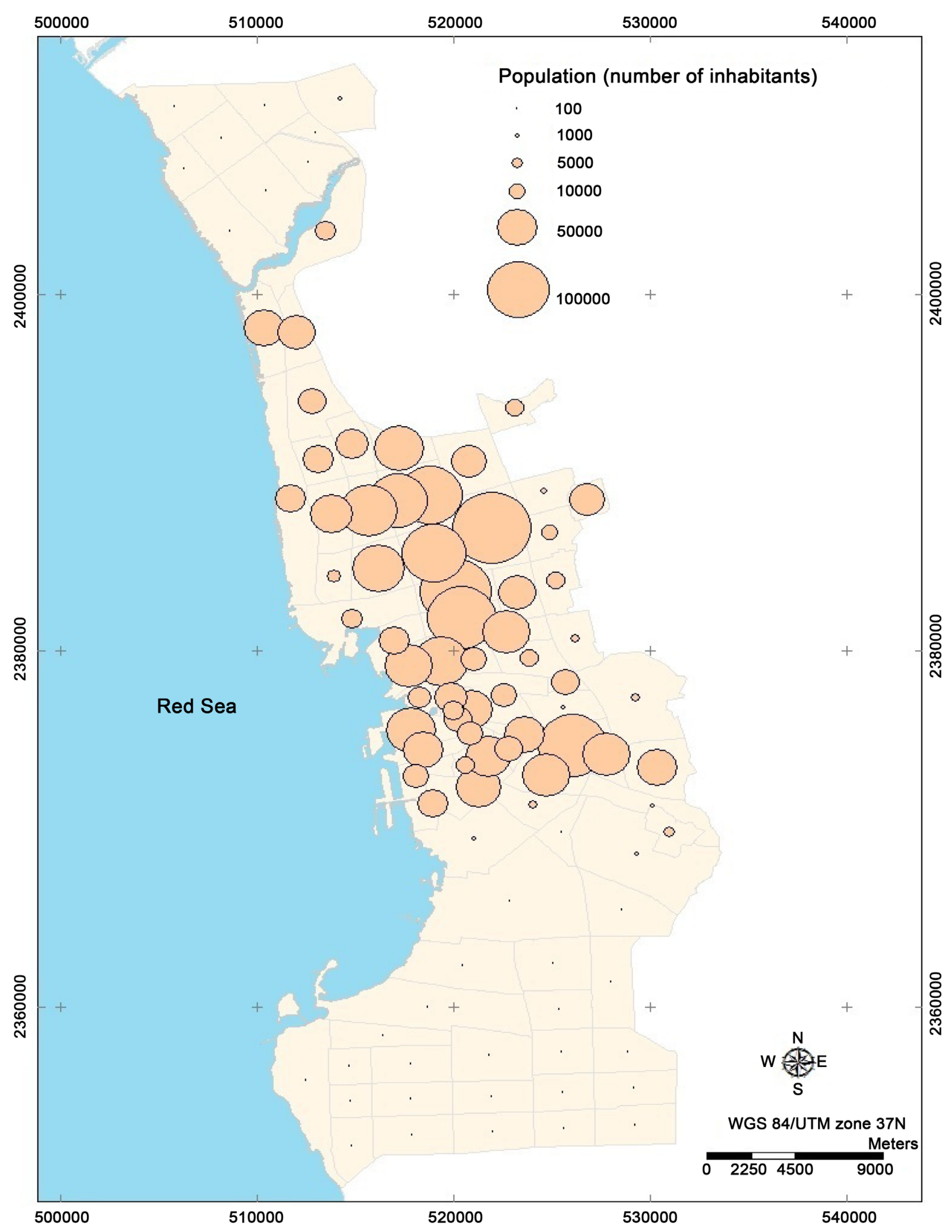

Figure 2. Population number by district in Jeddah City. 


\section{Methodology and Results}

The extraction of the land use map was done by classifying the Spot 5 image using ENVI image processing software. The goal of the classification techniques is to determine to which class is belonging each of the pixels in the image, following an approach where the accuracy of the results can be analyzed statistically (Bonn and Rochon, 1992). The chosen classification method is the spectral angle mapping (SAM). According to South \& Lusch (2004), the comparison between five supervised classification methods: Minimum Distance, Mahalanobis Distance, Maximum Likelihood, Spectral Angle Mapping, and the Cosine of the Angle Concept shows that Spectral Angle Mapping is the most suitable classification algorithm. Spectral Angle Mapper (SAM) is a physically-based spectral classification that uses an $n$-D angle to match pixels to reference spectra. The algorithm determines the spectral similarity between two spectra by calculating the angle between the spectra and treating them as vectors in a space with dimensionality equal to the number of bands. This technique, when used on calibrated reflectance data, is relatively insensitive to illumination and albedo effects. End member spectra used by SAM can come from ASCII files or spectral libraries, or you can extract them directly from an image (as Region Of Interest average spectra). SAM compares the angle between the end member spectrum vector and each pixel vector in $n$-D space. Smaller angles represent closer matches to the reference spectrum. Pixels further away than the specified maximum angle threshold in radians are not classified. SAM classification assumes reflectance data. However, if you use radiance data, the error is generally not significant because the origin is still near zero (Kruse et al., 1993). The simplest way to illustrate this method is to create a $2 \mathrm{D}$ scatter plot of an image spectrum and library spectrum in a two-band image (Figure 3). The classified image has to be afterward transferred to ESRI ArcGIS software. The GIS technique is actually an effective tool making the data analysis easier to handle large spatial data and provide high capabilities of analysis (Hamza et al., 2007).

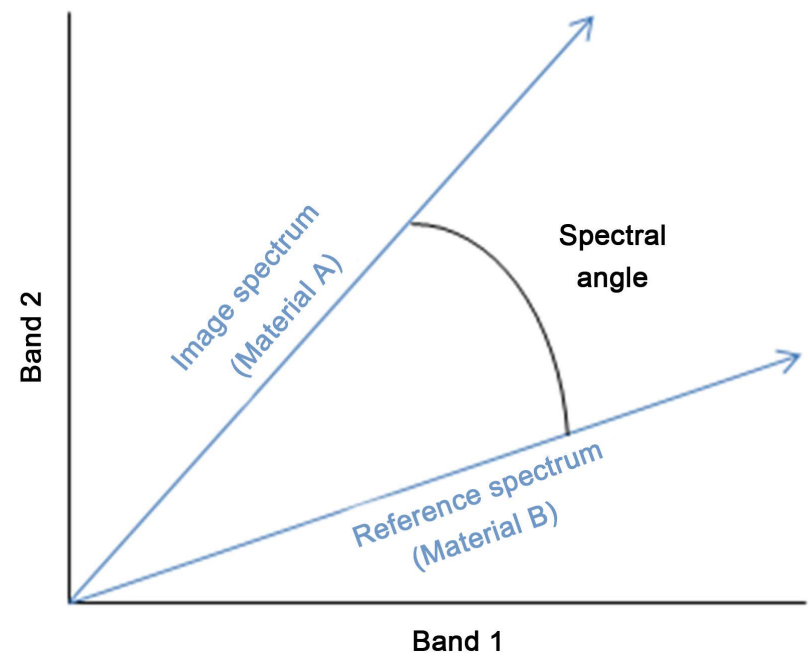

Figure 3. Concept of Spectral Angle Mapper (SAM). 
In the present study area, six types of Regions of Interest (ROI) were extracted: Continuous urban fabric, Discontinuous urban fabric, Green areas, Bare soil, Urban waste, Sea-Port. These ROIs were used as training sites to identify areas in the Spot 5 image following SAM supervised classification. The distinction between the different types of land use is based on the difference between spectral signatures of samples and verification on Google Earth Pro. The ENVI software is able, from various selected samples and after classification, to provide us the confusion matrix.

We were able in this study to extract the choropleth map by considering the totality of the area of Jeddah City, based on the districts, without particular distinction of the built-up areas. The extracted choropleth image was afterward transferred to ArcGIS ESRI GIS software under a shapefile vector format. The data related to the number of persons in the population and those relating to the area of Jeddah City districts were introduced in the fields of the attribute table of the shapefile. This will subsequently allow to calculate the population density in the study area (Population density = number of people/land area). The choropleth map is covering a total area of $752.661 \mathrm{sq} \cdot \mathrm{km}$; it shows population density values varying between 7 and 57,359 inhabitants per sq. km; these values were classed into five classes by using two different methods: the equal interval method and the Jenks method (Table 1 and Table 2 and Figure 4 and Figure 5).

The dasymetric method gives a better view of population distribution over a given area than conventional choropleth maps (Bielecka, 2005). Zones outside of the built areas were excluded from the dasymetric map. As we proceeded for the choropleth map, the dasymetric map was extracted from the Spot 5 image classified through SAM supervised classification. The population density was calculated as same. The extracted

Table 1. Area related to the different classes of population density in the choropleth map (Equal intervals classification).

\begin{tabular}{ccc}
\hline Population density (people per sq.km) & Area (sq.km) & Area (percentage of total surface area) \\
\hline $7-11,481$ & 642.848 & 85.436669 \\
$11,482-22,957$ & 97.7945 & 12.997207 \\
$22,957-34,431$ & 9.3917 & 1.248196 \\
$34,431-45,906$ & 1.9613 & 0.260664 \\
$45,906-57,379$ & 0.430875 & 0.057265 \\
\hline
\end{tabular}

Table 2. Area related to the different classes of population density in the choropleth map (Natural breaks, Jenks classification).

\begin{tabular}{ccc}
\hline Population density (people per sq.km) & Area $(\mathrm{sq} \cdot \mathrm{km})$ & Area (percentage of total surface area) \\
\hline $7-2482$ & 516.534003 & 68.64905 \\
$2482-7657$ & 105.358167 & 14.002443 \\
$7657-13,731$ & 69.512148 & 9.238391 \\
$13,731-20,031$ & 35.231679 & 4.682405 \\
$20,031-57,379$ & 25.791021 & 3.427711 \\
\hline
\end{tabular}




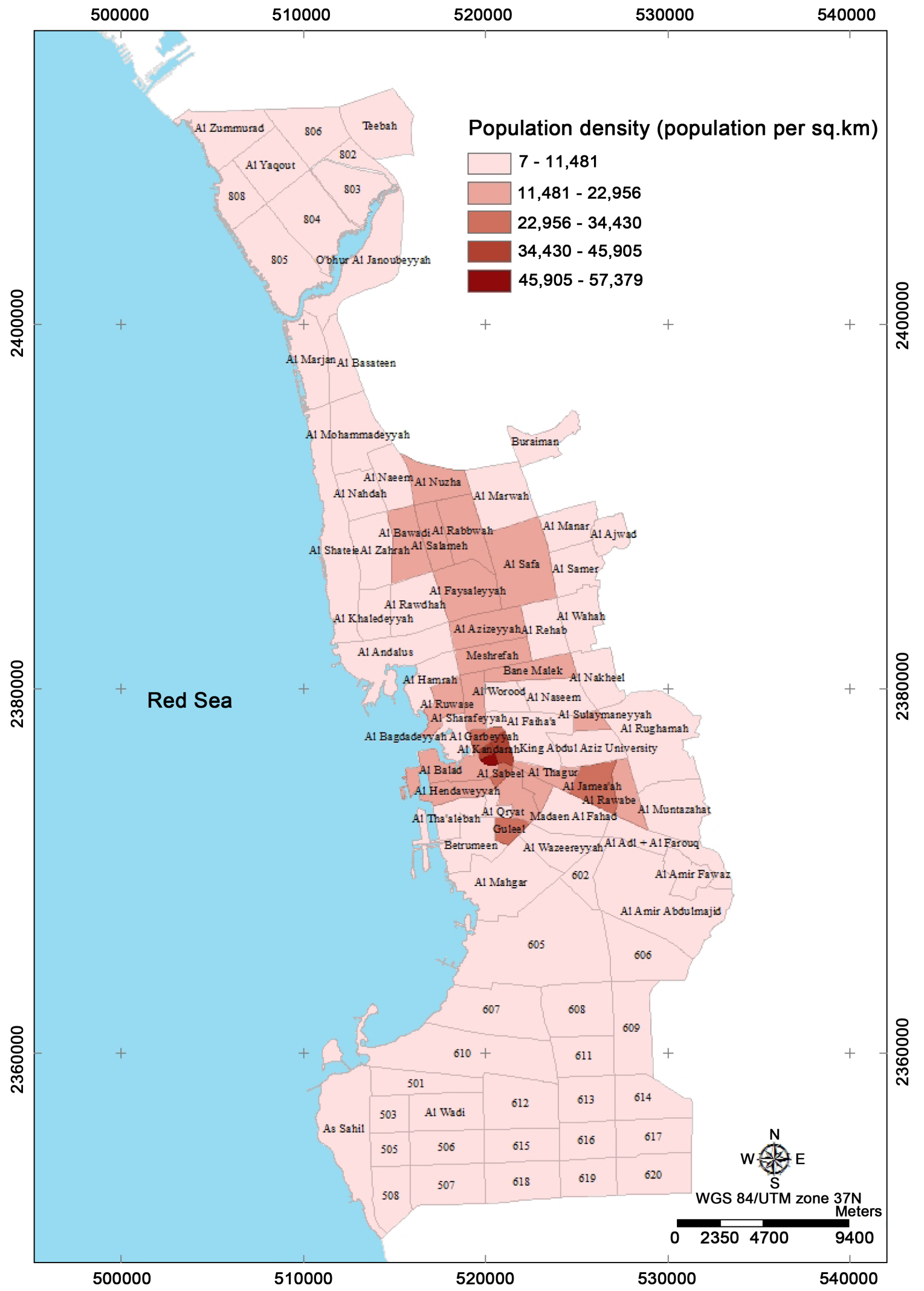

Figure 4. Choropleth map of Jeddah City (Equal intervals classification). 


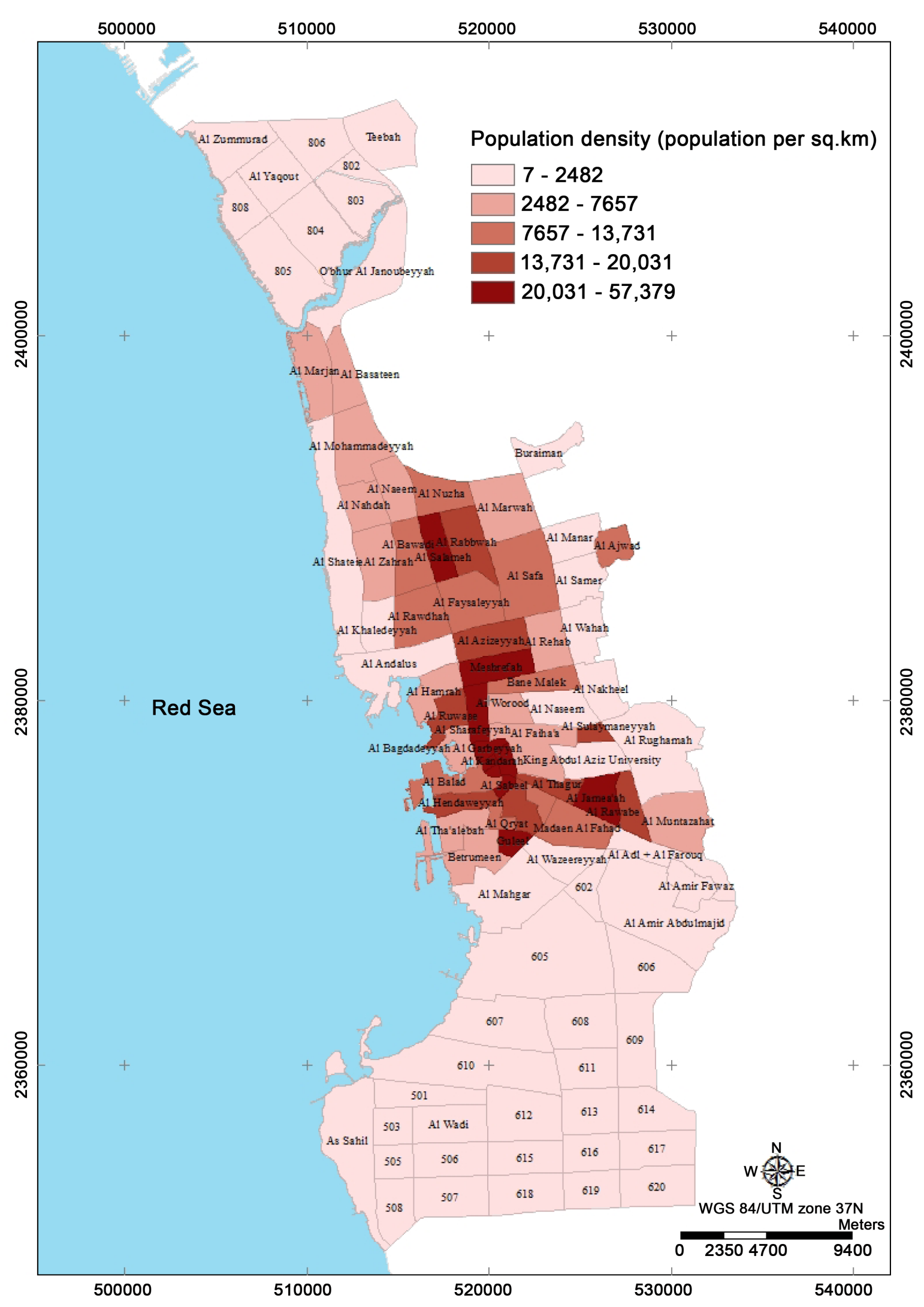

Figure 5. Choropleth map of Jeddah City (Natural breaks, Jenks classification). 
dasymetric map has a total area of only $244.321 \mathrm{sq} \cdot \mathrm{km}$ (752.661 sq. $\mathrm{km}$ in the choropleth map). The population density varies between 24 and 62,391; these values were classed into five classes by using two different methods: the equal interval method which shows the dissymmetrical distribution of the densities (Figure 6) and the Jenks method which is more respectful of the groups of densities (Figure 7). This latter has the advantages of portraying the distribution of small groups of densities with respect to the data physionomy and profile. Besides this, it may lead to different class limits over 2 statistical series (Table 3 and Table 4 and histograms Figure 8 and Figure 9).

\section{Discussion}

The use of high spatial resolution images, as the Spot 5 image used in this study, could help in the production of dasymetric map and then the representation of the real distribution of population density. These types of images would take into account the different types of built-up areas to better distribute the population densities.

The extracted dasymetric maps are more accurate than the choropleth maps, whether using the equal interval or the Jenks method. Moreover, we do think that this statement applies for the other partition methods. But the Jenks method fits the distribution of densities. The population density is calculated by taking into consideration only the built-up areas with a total area of 244.321 sq. Unlike in choropleth map, the entire surface of the study area is considered, even outside of built-up area (752.661 sq. $\mathrm{km}$ as a total area).

Table 3. Area related to the different classes of population density in the dasymetric map (Equal intervals classification).

\begin{tabular}{ccc}
\hline Population density (people per sq.km) & Area (sq.km) & Area (percentage of total surface area) \\
\hline $24-12,497$ & 169.70 & 69.46 \\
$12,497-24,970$ & 28.69 & 11.74 \\
$24,970-37,444$ & 32.51 & 13.30 \\
$37,444-49,917$ & 11.89 & 4.875 \\
$49,917-62,391$ & 1.52 & 0.625 \\
\hline
\end{tabular}

Table 4. Area related to the different classes of population density in the dasymetric map (Natural breaks, Jenks classification).

\begin{tabular}{ccc}
\hline Population density (people per sq.km) & Area $(\mathrm{sq} \cdot \mathrm{km})$ & Area (percentage of total surface area) \\
\hline $24-1844$ & 100.254 & 41.034 \\
$1844-7067$ & 39.568 & 16.195 \\
$7067-16,937$ & 42.880 & 17.551 \\
$16,937-30,175$ & 37.169 & 15.213 \\
$30,175-62,391$ & 24.447 & 10.006 \\
\hline
\end{tabular}




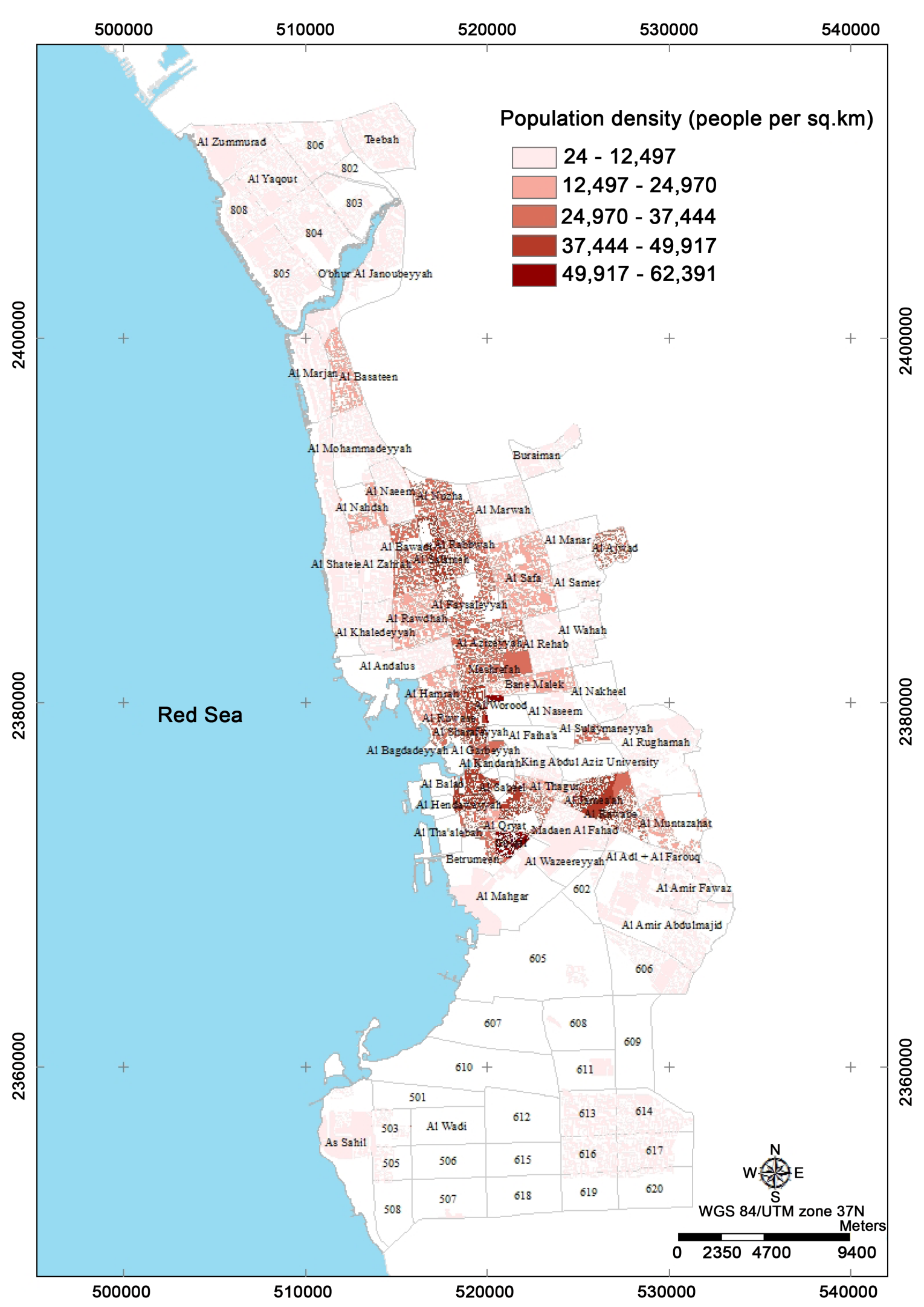

Figure 6. Dasymetric map of Jeddah City (Equal intervals classification). 
M. H. Hamza et al.

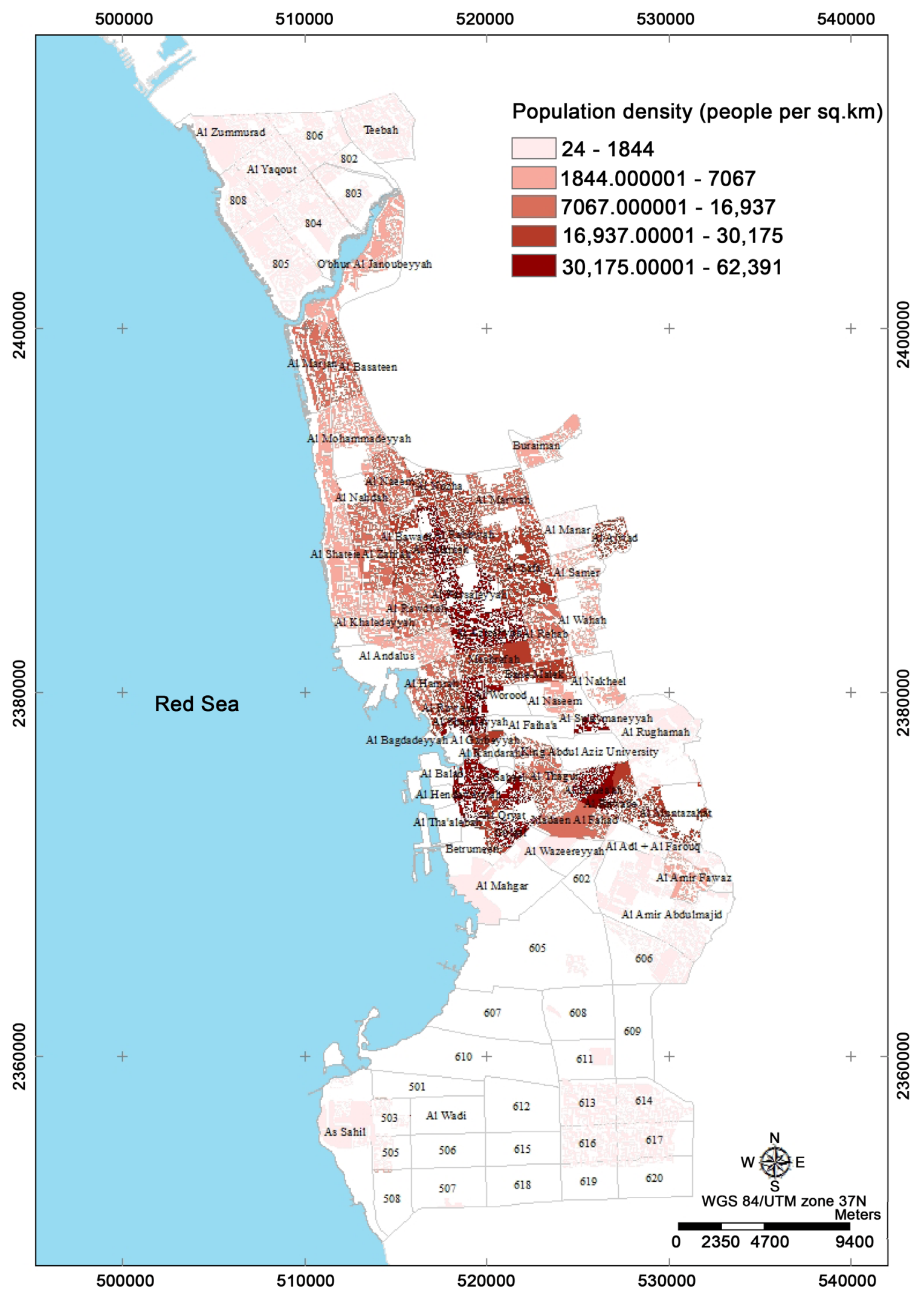

Figure 7. Dasymetric map of Jeddah City (Natural breaks, Jenks classification). 


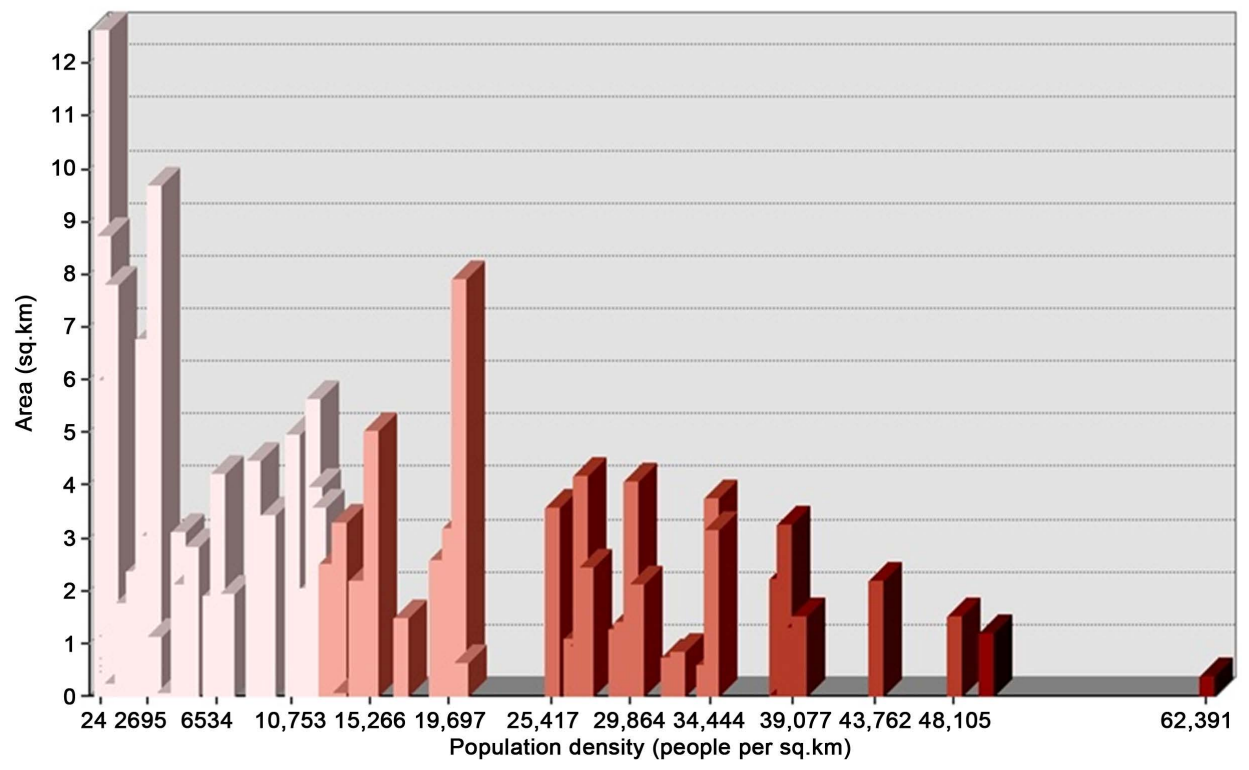

Figure 8. Graph showing areas related to the different classes of population density in the dasymetric map (Equal intervals classification).

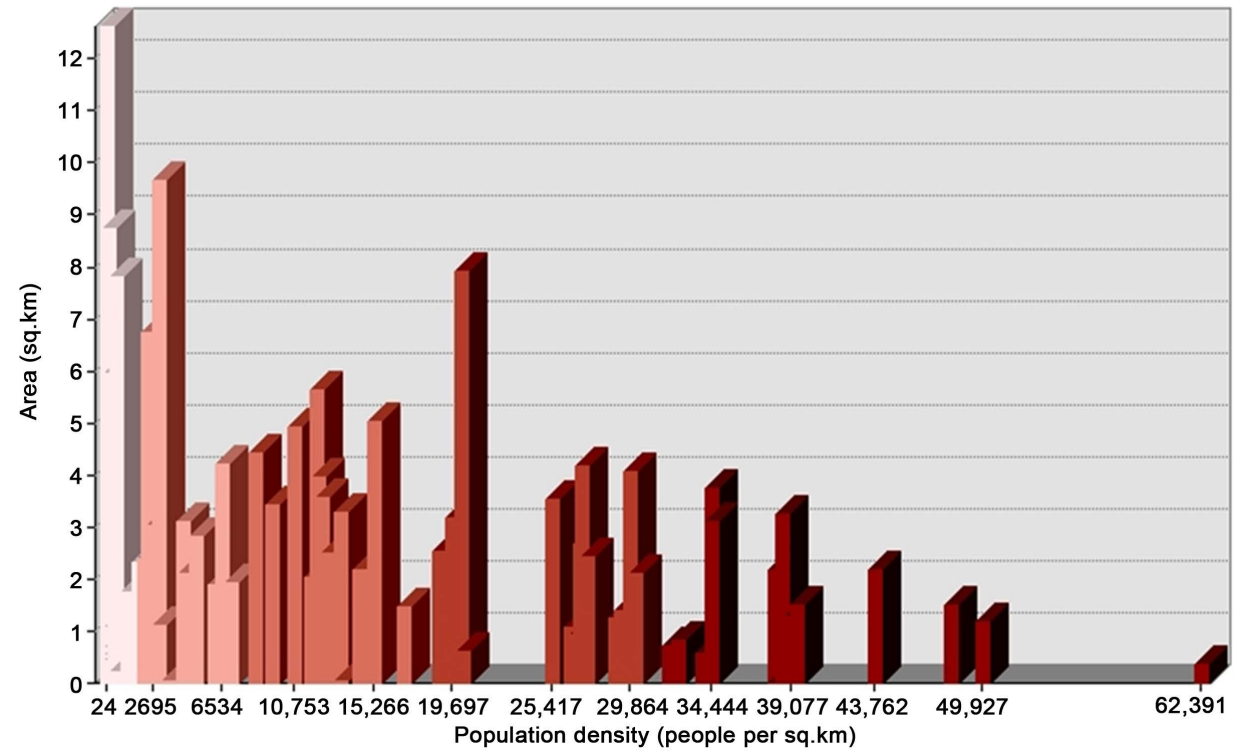

Figure 9. Graph showing areas related to the different classes of population density in the dasymetric map (Natural breaks, Jenks classification).

\section{Conclusion}

The primary contribution of this research is the presentation of two dasymetric maps of Jeddah City departing from population data, satellite image processing and other ancillary data. These dasymetric maps are more accurate than the classic choropleth maps usually used when portraying population density because they take into account only the built-up areas. For that, two partition methods were used: the equal intervals and the Natural breaks methods. Now, we know that Jeddah City has numerous unbuilt 
spaces or even built spaces that are inhabited. These spaces were deduced from processing the satellite image Spot 5 (2.5 meters resolution) of Jeddah City. These images were used to extract the land use types by classifying the image using ENVI image processing software. The used classification method was the spectral angle mapping (SAM). The classified images were transferred to the GIS software ESRI ArcGIS under a shapefile vector format. This was essential to add the data related to the number of individuals in the population and those relating to the area of Jeddah City in the fields of the attribute tables.

This study can be done in the next years for other cities in the Kingdom of Saudi Arabia.

\section{Acknowledgements}

This project was funded by the Deanship of Scientific Research (DSR) at King Abdulaziz University, Jeddah, under grant No. G-540-125-1434. The authors, therefore, acknowledge with thanks DSR for technical and financial support. Dr. Mohamed Hafedh HAMZA, Principal Investigator.

\section{References}

Ajmi, M., Hamza, M. H., Labiadh, M., Yermani, M., Ben Khatra, N., Al-Thubaiti, A. S., Moharrem, I. A., \& El Arrim, A. (2014). Setting up a Spatial Data Infrastructure (SDI) for the ROSELT/ OSS Network. Journal of Geographic Information System, 6, 150-161. http://dx.doi.org/10.4236/jgis.2014.62016

Bielecka, E. (2005). A Dasymetric Population Density Map of Poland. ICC2005-International Cartographic Conference, Corunna.

http://www.cartesia.org/geodoc/icc2005/pdf/oral/TEMA5/Session\%209/ELZBIETA\%20BIELE CKA.pdf

Bonn, F., \& Rochon, G. (1992). Précis de télédétection volume 1: Principes et méthodes. SainteFoy: Presse de l'université du Québec/AUPELF, 485 p.

Dhieb, M. (1991a). Deux exemples de conception de planches d'atlas: La répartition de la population en Tunisie. ICA Proceedings, "Mapping The Nations", Bournemouth, 23 September-1 October 1991. (In French)

Dhieb, M. (1991b). La représentation cartographique des densités de population urbaine: Aspects méthodologiques. Revue Tunisienne des Sciences Sociales No. 110, Tunis: CERES. (In Arabic)

Dhieb, M. (1995). La répartition spatiale de la population tunisienne d'après les premiers résultats du recensement de 1994. Revue Tunisienne de Géographie No. 28, FSHS de Tunis. (In French)

Hamza, M. H., Added, A., Rodriguez, R., Abdeljaoued, S., \& Ben Mammou, A. (2007). A GISBased DRASTIC Vulnerability and Net Recharge Reassessment in an Aquifer of a Semi-Arid Region (Metline-Ras Jebel-Raf Raf Aquifer, Northern Tunisia). Journal of Environmental Management, 84, 12-19. http://dx.doi.org/10.1016/j.jenvman.2006.04.004

Jaullt, R., \& Serradj, A. (2011). Les cartes dasymétriques et l'apport des images satellitaires dans la représentation de la densité de la population dans le gouvernorat élargi de Kairouan en Tunisie. SIG 2011, Conférence Francophone ESRI, Versailles, 5-6 Oct 2011.

Kruse, F. A., Lefkoff, A. B., Boardman, J. B., Heidebrecht, K. B., Shapiro, A. T., Barloon, P. J., \& Goetz, A. F. H. (1993). The Spectral Image Processing System (SIPS)-Interactive Visualization and Analysis of Imaging spectrometer Data. Remote Sensing of Environment, 44, 145- 
163. http://dx.doi.org/10.1016/0034-4257(93)90013-N

McCleary Jr., G. F. (1969). The Dasymetric Method in the Thematic Cartography. Unpublished Ph.D. Dissertation, Madison: University of Wisconsin.

Petrov, A. (2012). One Hundred Years of Dasymetric Mapping: Back to the Origin. The Cartographic Journal, 49. http://dx.doi.org/10.1179/1743277412Y.0000000001

Sleeter, R., \& Gould, M. (2007). Geographic Information System Software to Remodel Population Data Using Dasymetric Mapping Methods. US Geological Survey Techniques and Methods $11-C 2,15 \mathrm{p}$.

South, S., Qi, J., \& Lusch, D. (2004). Optimal Classification Methods for Mapping Agricultural Tillage Practices. Remote Sensing of Environment, 91, 90-97. http://dx.doi.org/10.1016/j.rse.2004.03.001

Wright, J. K. (1936). A Method of Mapping Densities of Population with Cape Cod as an Example. Geographical Review, 26, 103-110. http://dx.doi.org/10.2307/209467

Submit or recommend next manuscript to SCIRP and we will provide best service for you:

Accepting pre-submission inquiries through Email, Facebook, LinkedIn, Twitter, etc. A wide selection of journals (inclusive of 9 subjects, more than 200 journals)

Providing 24-hour high-quality service

User-friendly online submission system

Fair and swift peer-review system

Efficient typesetting and proofreading procedure

Display of the result of downloads and visits, as well as the number of cited articles

Maximum dissemination of your research work

Submit your manuscript at: http://papersubmission.scirp.org/

Or contact cus@scirp.org 